\title{
Campanhas online e twitter: a interação entre campanhas e eleitores nas eleições presidenciais brasileiras de 2010'
}

\section{Online Campaigning and Twitter: communicative interaction between campaigns and voters in 2010 Brazilian presidential election}

Camilo de Oliveira Aggio

Doutor em Comunicação e Cultura Contemporâneas pela Universidade Federal da Bahia (UFBA). Professor do Programa de PósGraduação em Comunicação e Cultura Contemporâneas da Universidade Federal da Bahia. Pesquisador associado ao Centro de Estudos Avançados em Democracia Digital e Governo Eletrônico (CEADD).

<camiloaggio@gmail.com>

\section{RESUMO}

Desde 1996, pesquisadores se debruçam sobre especulações de ordem teórica e exames empíricos para refletir sobre quais os ganhos democráticos e estratégicos da interação direta, via tecnologias digitais entre candidatos e partidos com eleitoresEspecificamente, a pesquisa aqui apresentada pretende avaliar a frequência de uso de recursos interativos por candidatos à presidência do Brasil em 2010 no Twitter, além de propor e aplicar uma metodologia que permita aferir com precisão o quão efetivas foram tais interações e com quais finalidades políticas e estratégicas foram empregadas. Concluise que os três principais candidatos à presidente do Brasil em 2010 apresentaram índices significativos de interação. No entanto, a comunicação horizontal das campanhas não serviu majoritariamente à discussão de ideias, posicionamentos e projetos políticos.

Palavras-chave: Campanhas online. Eleições. Twitter.

\begin{abstract}
Since 1996, researchers from around the world discusses, theoretically and empirically, about which democratic and strategic benefits derives from online direct communication between candidates, political parties and voters as well as how often and with what purpose direct communication is adopted. Specifically, this paper aims at evaluate the frequency of interactive features adoption by the three main candidates running for president of Brazil in 2010 on twitter using a methodological approach to distinguish real interactions between campaigns and voters from messages that contains interactive features but are not translated in real discursive exchanges. I conclude that the three main candidates interacted in significant levels. Notwithstanding, the direct interactions between the three main campaigns and Twitter users were not used to discuss ideas, plans and positions on political issues.
\end{abstract}

Keywords: Online Campaigning. Election. Twitter.

A comunicação horizontal entre campanhas e eleitores é uma das questões mais recorrentes na pesquisa em campanhas online. Pesquisadores como Jennifer Stromer-Galley vislumbram na comunicação digital a possibilidade de campanhas prestarem esclarecimentos sobre projetos e posições de seus candidatos diretamente a cidadãos ou grupos organizados,

1 Estudo desenvolvido com financiamento do CNPq e da CAPES. 
de discutirem ideias e planos de ação com diferentes atores sociais e políticos e, sob uma perspectiva mais rigorosa de participação política, de cidadãos poderem desempenhar papéis ativos na construção colaborativa de planos de governo (Stromer-Galley, 2013).

Trata-se de um esforço teórico - bem como de uma reivindicação social e política - que parte de um modelo ideal, normativo, sobre como deveriam ser as campanhas eleitorais em ambientes online. Em outras palavras, o debate acerca das qualidades e ganhos epistêmicos, sociais e políticos da interação entre eleitores e campanhas, tem a mesma matriz participacionista das perspectivas teóricas que vislumbram na internet possibilidades efetivas de incremento da democracia mediante o aumento da porosidade do Estado e a consequente influência civil nas esferas de decisão política.

Postula-se, portanto, que para além da função elementar de qualquer campanha eleitoral - a saber, ganhar votos e eleger líderes - a comunicação digital pode fazer com que campanhas eleitorais se tornem parte do ideal de democracia forte ou fortalecimento da democracia (strong democracy) defendida por Benjamin Barber (Stromer-Galley, 2014).

Embora a interatividade seja tratada com entusiasmo na literatura - tanto sob o ponto de vista de seu valor democrático quanto como recurso estratégico - as evidências empíricas, acumuladas desde 1996, mostram que campanhas online em diferentes realidades nacionais seguiram um padrão de funcionamento pouco ou nada interativo (Aggio, 2013; Howard, 2005; Davis e Owen, 1998; Carlson e Göran, 2001; Farnsworth e Owen, 2004; Gibson e outros, 2003; Kluver, 2004; Ward e Gibson, 2003; Druckman e outros, 2007; Lusoli, Ward, 2005; Park e Perry, 2008; Stromer-Galley, 2014; Tkach-Kawasaki, 2003; Fernandez, 2005; Schweitzer, 2005). No entanto, com o advento e popularização dos sites para redes sociais, esse panorama passou a mudar.

Sites como Facebook e Twitter são as "praças públicas" por onde a maioria dos que acessam a internet busca informações e interage, de modos e em graus variados, com outras pessoas, grupos ou instituições. Por um lado, portanto, são nessas plataformas sociais que se encontram eleitores e apoiadores em potencial para que as campanhas atuem em busca de votos e mobilização. Por outro lado, o ingresso nessas plataformas pressupõe se adequar, em certa medida, à sociabilidade estabelecida por seus usuários.

No universo atual de plataformas para redes sociais, o Twitter continua sendo o social media mais pregnante politicamente (Parmelee, John; Bichard, Shannon, 2012), embora não seja mais tão popular quanto o Facebook. De acordo com o estudo "Twiplomacy" realizado pela agência de consultoria 
Burson-Marsteller, há cerca de 172 chefes de Estado e do governo em todo o mundo que possuem contas no Twitter (Burson-Marsteller, 2015). No Brasil, a presença de políticos também é expressiva, como atestam Marques e Aquino (2013).

Essa representação da política institucional no Twitter atrai, naturalmente, cidadãos, grupos, organizações e instituições interessadas no debate político e em ações que visem a monitorar e influenciar o centro da decisão política. Neste corpo político e social, encontram-se eleitores e potenciais militantes que devem (e são) considerados nas estratégias de campanha. Ademais, considerandose que grande parte da sociabilidade estabelecida no Twitter se assenta em dinâmicas de interação discursiva entre seus usuários, é plausível esperar que campanhas políticas adotem parte dessas dinâmicas em suas estratégias para atingir segmentos do eleitorado.

Ao contrário das fases anteriores à popularização dos sites para redes sociais, em que as campanhas não tornavam disponíveis recursos como e-mail, fóruns e salas de bate-papo para a comunicação horizontal em seus websites (Conway, Kenski, Wang, 2013; Macnamara, Kenning, 2010; Bruns, Highfield, 2013; Marques, Silva, Matos, 2013; Baxter, Marcella, 2012; Graham, Broersma, Hazelhof, 2013; Holotescu et al., 2010; Grusell, Nord, 2012; Klinger, 2013), pesquisas recentes demonstram que muitos partidos e candidatos lançam mão de recursos interativos disponíveis no Twitter (Conway, Kenski, Wang, 2013; Bruns, Highfield, 2013; Aragón et al., 2013; Baxter, Marcella, 2012; Marques, Silva e Matos, 2013; Grusell, Nord, 2012; Klinger, 2013; Holotescu et al., 2010; Macnamara, Kenning, 2010; Enli, Skogerbo, 2013; Graham, Broersma, Hazelhof, 2013).

É, portanto, no terreno das discussões sobre a interação e a comunicação das campanhas no Twitter que este trabalho se situa. Especificamente, a pesquisa aqui apresentada pretende avaliar os níveis do uso de recursos interativos por candidatos à presidência do Brasil em 2010 no Twitter, além de propor e aplicar uma metodologia que permita aferir com precisão o quão efetivas foram tais interações e a quais funções políticas e estratégicas serviram.

\section{Twitter, recursos interativos e eleições brasileiras de 2010}

As eleições de 2010 foram as primeiras da história do Brasil em que o emprego dos sites para redes sociais por campanhas eleitorais foi permitido. Isto porque, até então, o Tribunal Superior Eleitoral (TSE) insistia em impor um anacronismo às campanhas online brasileiras ao vedar o uso de quaisquer 
recursos de comunicação digital que não os websites de candidatos e partidos (Gomes e outros, 2013).

Em razão desse ineditismo, as campanhas para presidente do Brasil em 2010 foram escolhidas como recorte de pesquisa deste trabalho, mas essa não é a única razão. $O$ campo de pesquisa sobre campanhas online no Brasil ainda carece de estudos que lancem luz sobre se e como as campanhas brasileiras estão, efetivamente, utilizando as possibilidades de comunicação horizontal do Twitter para interagir. Soma-se a essas duas razões a tentativa de oferecer uma proposta metodológica que permita distinguir interações aparentes daquelas efetivas.

São dois os recursos que permitem a comunicação horizontal no Twitter: menções (mentions) e replicações (retweets) ${ }^{2}$. Em ambos os casos, uma ou mais contas de usuários do site (ex. @fulano) são mencionadas nas mensagens, ativando o sistema de notificações dos mencionados. Os dois recursos estimulam o engajamento em conversas e discussões, uma vez que todos indivíduos mencionados tomam conhecimento do endereçamento que lhes foi feito. No entanto, a simples presença de menções ou replicações nessas mensagens não são suficientes para garantir que houve, de fato, interação entre a parte ou as partes mencionadas e o agente da menção. A replicação de uma mensagem pode indicar apenas a reprodução de uma mensagem sem qualquer traço de interação discursiva entre usuários. Pode significar apenas um endosso ao conteúdo da mensagem "retuitada". O mesmo pode acontecer com as menções na medida em que o enunciado da mensagem não convoque qualquer reação do usuário mencionado ou carregue qualquer indício de existência de alguma troca discursiva entre as partes.

São essas características técnicas da comunicação do Twitter que exigem cuidados metodológicos e analíticos, principalmente no que tange ao objeto desta pesquisa. Aferir o quanto as campanhas estão interagindo com outros perfis no Twitter demanda que cada tweet da amostra escolhida seja analisado separadamente a fim de que seja constatado, ou não, algum tipo de interação discursiva entre campanhas e outros usuários do site.

No âmbito das pesquisas dedicadas ao uso do Twitter por campanhas, todos os trabalhos que fazem parte da revisão da literatura deste artigo

2 O termo replicações deve ser entendido em sua acepção de "reprodução" e não de resposta. Trata-se de uma tradução livre para o termo retweet que se refere ao recurso para a reprodução de mensagens no Twitter. 
empreenderam apenas análises quantitativas para identificar a presença do uso dos recursos interativos, com exceção de Bruns e Highfield (2013) e Graham, Broersma e Hazelhof (2013) - que analisaram campanhas australianas de 2010 e do Reino Unido no mesmo ano, respectivamente. Com exceção dos dois trabalhos mencionados, predomina-se a equivalência entre a presença de menções e replicações à interação discursiva entre campanhas e usuários do Twitter.

Desse modo, as pesquisas empíricas que cuidam da análise do Twitter em campanhas eleitorais precisam de um modelo metodológico que, primeiro, (a) permita identificar, efetivamente, a existência ou não de comunicação horizontal genuína entre eleitores e campanhas e, em segundo, (b) faz-se necessário aferir quais os propósitos e funcionalidades da comunicação direta entre partidos e candidatos com eleitores. Ou seja, a quais finalidades servem essas interações? Quais seus propósitos e contribuições para comunicação eleitoral?

Mediante tais indagações, este trabalho analisa (a) a frequência de utilização de recursos interativos por parte das campanhas para presidente do Brasil em 2010, (b) as funções atribuídas à essas mensagens (se para divulgar agendas, discutir projetos e posicionamentos ou exibir capital social, por exemplo) e (c) a proporção de mensagens contendo mentions e retweets que, efetivamente, serviram à interação discursiva entre as campanhas e outros perfis do Twitter.

\section{Metodologia e corpus de análise}

O corpus de análise é formado pelos perfis dos três principais candidatos à presidência da República do Brasil em 2010: Dilma Rousseff (Partido dos Trabalhadores/PT), José Serra (Partido da Social Democracia Brasileira/PSDB) e Marina Silva (Partido Verde/PV).

A posição dos candidatos nas sondagens de opinião - ou seja, seus respectivos capitais eleitorais - foi o critério adotado para a seleção. Desde abril de 2010, mês de início da coleta de dados, até o fim da disputa no primeiro turno, os três principais institutos de pesquisa brasileiros (Datafolha, lbope e Vox Populi) mostraram que a disputa se concentrara em Dilma Rousseff, José Serra e Marina Silva. Respectivamente, primeiro, segundo e terceiro colocados nas sondagens realizadas. ${ }^{3}$

3 Os resultados das pesquisas eleitorais realizadas para o pleito presidencial de 2010 podem ser acessados a partir do verbete do Wikipédia dedicado ao assunto ( $\leq$ http://pt.wikipedia.org/wiki/Pesquisas de opini $\% \mathrm{C} 3 \% \mathrm{~A} 30$ na elei $\% \mathrm{C} 3 \% \mathrm{~A} 7 \% \mathrm{C} 3 \% \mathrm{~A} 30$ presidencial brasileira de 2010>) 
Foram consideradas todas as publicações feitas entre 11 de abril e 31 de outubro de 2010. A data de início foi escolhida por se referir ao dia em que a candidata Dilma Rousseff publicou sua primeira mensagem no Twitter, reproduzida abaixo:

“@dilmabr: Bom dia, boa tarde, boa noite p/ quem me lê em qqer lugar do mundo. Começo hoje minha aventura no Twitter. Quero aprender c/ vcs"

Ao todo, foram coletados, categorizados e analisados 3.578 tweets publicados nos três perfis selecionados ao longo do período definido: de 11 de abril a 31 de outubro. Esse intervalo compreende o período definido como pré-campanha (11 de abril a 05 de junho), da disputa do 1 ํoturno (06 de junho a 5 de outubro) e da disputa no 2o turno (de 06 a 31 de outubro). Todas as médias foram calculadas proporcionalmente ao período em que as campanhas se mantiveram ativas, ou seja, embora um dos três candidatos tenha ficado de fora da disputa no segundo turno, a análise comparativa não foi comprometida.

\section{Análise de Conteúdo: Funções estratégicas e políticas das interações}

Para que fossem apreendidas as funções e significados atribuídos à interação pelos três candidatos, foram adotadas e adaptadas 11 categorias de análise de conteúdo concebidas por Gomes, Reis, Duarte e Marques (2010). São elas: (a) Agenda; (b); Exibição de Capital Político, (c); Exibição de Capital Social; (d) Posicionamento; (e) Divulgação de notícias; (f) Campanha Negativa; (g) Tentativa de Criar Engajamento; (h) Pessoal/Intimidade; (i) Promessas e Propostas; (j) Realizações Passadas e (I) Outros.

\section{Interação Discursiva: Para além da análise quantitativa}

Para que as funções dos recursos interativos fossem identificadas, foram criadas categorias, indicadores e variáveis divididos em três grupos analíticos: (i) identificação das mensagens contendo menções e replicações através de procedimentos quantitativos; (ii) análise de conteúdo dessas mensagens a fim de identificar a quais finalidades serviram e (ii) discriminação das mensagens contendo interações efetivas.

\section{A natureza das menções e replicações}

A classificação das mensagens contendo um dos dois recursos voltados à interação discursiva foi feita a partir de um critério binário de análise. Nesta seção, em específico, cabe distinguir aqueles tweets a serviço de uma simples 
menção - sem indícios de interação entre perfis - daqueles contendo elementos enunciativos que comprovem uma ação de reciprocidade da campanha, seja em forma de resposta, comentário ou indicação de hyperlinks para fins de esclarecimento sobre alguma questão.

\section{Tabela 1}

\begin{tabular}{|c|c|c|}
\hline Variável & Menções & Replicações \\
\hline Referencial & R1 & R2 \\
\hline Discursiva & D1 & D2 \\
\hline
\end{tabular}

Fonte: O autor (2016)

A variável "referencial" se aplica às mensagens contendo menções (R1) quando não há presença de algum tipo de manifestação em resposta a um perfil e que, portanto, serve apenas como referência no enunciado, conforme ilustra o exemplo em que a candidata Marina Silva saúda seus adversários:

\footnotetext{
“Aproveito a oportunidade para cumprimenta-los diretamente @ joseserra_, @dilmabr, @cirofgomes e @pliniodearruda <http://migre. me/wN2h>" (Tweet publicado no perfil da candidata Marina Silva em 15 de abril de $2010^{\prime \prime}$
}

Nas mensagens contendo retweets, esta variável (R2) se refere à simples reprodução de mensagens de outro perfil. Há alguma interação no ato de reproduzir um tweet, mas sem quaisquer elementos que configurem uma ação de reação discursiva da campanha. $A$ intenção é apenas a de redirecionar mensagens de terceiros a seus seguidores:

“RT @felipe_autran: Os caras-pintadas de Minas: @joseserra_@ aecioneves e @gabrielazevedo: <http://twitpic.com/2xmdr8> \#verdeamarelovermelho"(Tweet publicado no perfil do candidato José Serra em 15 de outubro de 2010)

A variável "discursiva" aplicada às menções (D1) abarca mensagens cujo enunciado evidencia uma ação discursiva como reação a alguma mensagem publicada pelo perfil mencionado. Considera-se tanto agradecimentos por demonstrações de apoio (ou outras razões) quanto respostas a dúvidas e questões, como exemplificado abaixo. 


\begin{abstract}
“@Raffa13br já opinei sim sobre Ficha Limpa. Sou a favor, na forma aprovada da Câmara, que impede candidatura de condenados por colegiados" (Tweet publicado no perfil da candidata Dilma Rousseff em 19 de maio de 2010)
\end{abstract}

As replicações consideradas discursivas (D2) se referem a quaisquer manifestações textuais do perfil que acompanhem a reprodução de tweets de outros usuários do Twitter. Considera-se, portanto, tanto a inserção de onomatopeias para expressar a emoção de uma reação à mensagem, como agradecimentos, esclarecimentos, comentários triviais e hiperlinks que contemplem alguma solicitação do autor da mensagem replicada. O exemplo abaixo ilustra essa classificação.

"Vote tranquilo. Reajuste garantido. RT @rzaen Queria votar em ti, mas sou funcionário do BB e tenho medo de ficar +10 anos sem reajuste..." (Tweet publicado no perfil do candidato José Serra em 23 de outubro de 2010)

\title{
Análise empírica
}

Esta seção se divide em três partes. A primeira apresenta e discute a proporção de mensagens contendo recursos para a interação discursiva no universo de tweets publicados por cada campanha e na soma de todas as mensagens publicadas nos perfis dos três candidatos. As categorias "menções" e "replicações" representam a presença dos recursos para interação discursiva enquanto a categoria "broadcasting" se refere aos tweets desprovidos desses recursos. A segunda parte destina-se à análise de conteúdo das mensagens contendo mentions e retweets. Foram utilizadas 11 categorias analíticas que permitem identificar o propósito político e estratégico das interações das campanhas no Twitter.

Por fim, são apresentados os resultados da distinção entre mensagens voltadas efetivamente à interação entre campanha e público e aquelas que, apesar da presença dos recursos para a interação, não serviram efetivamente à interação discursiva. Os resultados dessa última etapa de análise permitirão afirmar com segurança o quão interativas foram as campanhas presidenciais no Twitter em 2010.

\section{Distribuição quantitativa dos recursos interativos}

Os três candidatos distribuíram a aplicação de recursos de interação discursiva em proporções distintas. Enquanto Marina Silva dedicou 43,3\% de todos os seus tweets a menções e replicações, Dilma Rousseff os utilizou em 
$17,6 \%$ de suas mensagens. José Serra, por outro lado, fez da sua comunicação no Twitter um canal voltado majoritariamente para a interação com outros usuários. Das 1.687 mensagens publicadas pelo candidato do PSDB, 1.015 foram feitas com a utilização de mentions e retweets, ou seja, $60,2 \%$ de todos os tweets publicados.

\section{Gráfico 1: Dilma Roussef - Interação Discursiva}

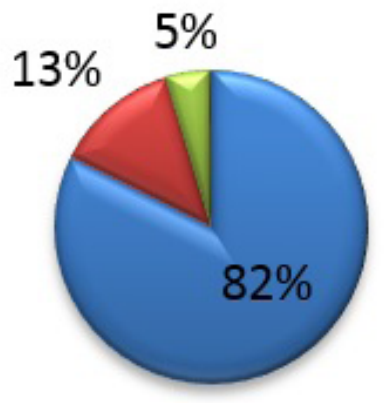

Broadcasting

Menções

Replicações

Fonte: $\mathrm{O}$ autor (2016)

Embora o candidato do PSDB se destaque na utilização dos dois recursos, a marca atingida por Marina Silva também é significativa. A candidata do PV dedicou quase metade de suas publicações a alguma forma de comunicação direta com outros usuários do Twitter.

\section{Gráfico 2: José Serra - Interação Discursiva}

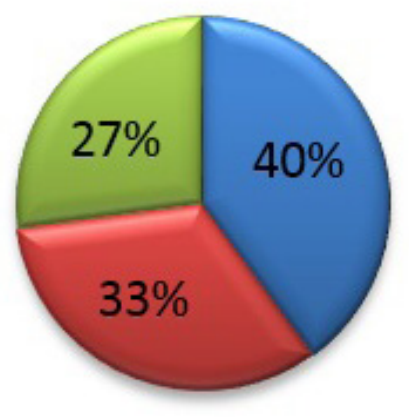

Broadcasting

Menções

Replicações

Fonte: O autor (2016)

Conforme demonstrado no gráfico 3,82\% de todas as publicações da campanha de Dilma Rousseff foram voltados a enunciados sem quaisquer 
sinais de comunicação horizontal. A grande parte, portanto, respeitou o modelo broadcasting.

q Gráfico 3: Marina Silva - Interação Discursiva

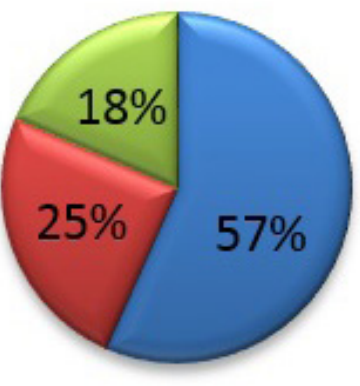

Broadcasting

Menções

Replicações

Fonte: O autor (2016)

Considerando o conjunto de evidências empíricas de que se têm conhecimento neste trabalho, pode-se considerar que o padrão brasileiro de campanha no Twitter, referente ao recorte das eleições presidenciais de 2010, se alinha às experiências com os maiores níveis de utilização de recursos para a interação discursiva (Conway, Kenski, Wang, 2013; Bruns, Highfield, 2013; Graham, Broersma, Hazelhof, 2013; Macnamara, Kenning, 2010; Enli, Skogerbo, 2013).

— Gráfico 4: Geral - Interação Discursiva

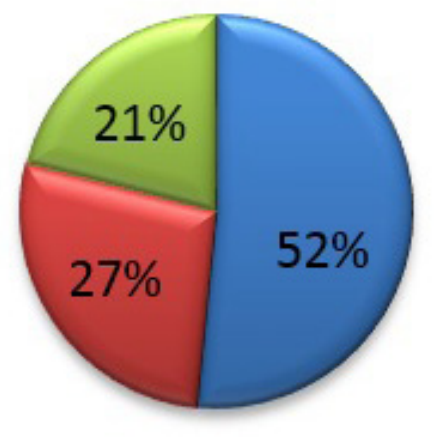

Legenda badcasting

$\square$ Menções

Replicações

Fonte: O autor (2016) 
Analisando os tweets publicados pelos três candidatos ao longo de todo o período da amostra, verifica-se que dentre as 3.578 mensagens postadas, 1.732 foram compostas de mentions e retweets. Considerando esse somatório, constata-se que quase metade $(48,4 \%)$ das mensagens publicadas pelas campanhas para presidente do Brasil em 2010 no Twitter sugerem algum tipo de interação entre campanhas e outros usuários do site, conforme os registros do gráfico 4.

\section{Análise de Conteúdo: Funções estratégicas dos recursos interativos}

\section{Marina Silva}

Conforme exposto no Gráfico 5, Marina Silva usou o recurso de menções para interagir com o intuito de esclarecer seus posicionamentos, em primeiro lugar, seguido de promessas e propostas, mensagens classificadas como "outros" e tweets voltados ao engajamento. Há, portanto, evidências de que a então candidata do Partido Verde tratou de questões políticas importantes na comunicação direta com outros perfis do Twitter.

\section{Gráfico 5: Marina Silva - Análise de conteúdo - Menções}

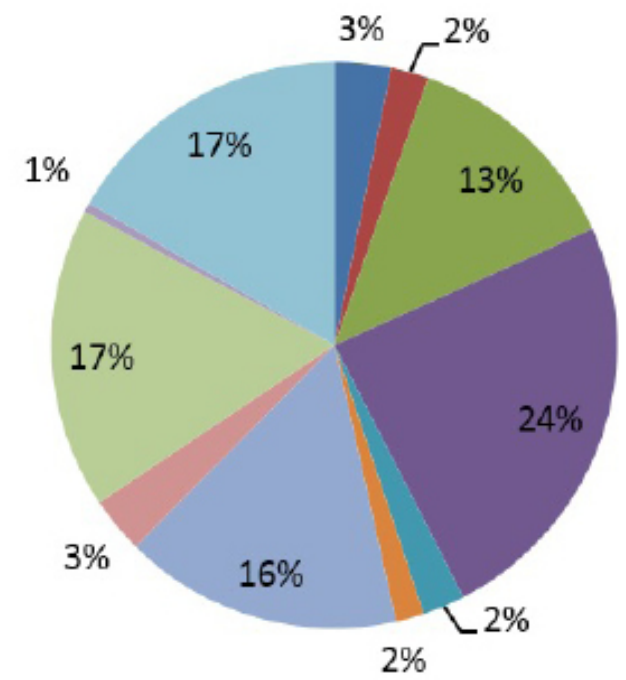

- Agenda

- Exibição de Capital Político

Exibição de Capital Social

- Posicionamento

- Divulgação de Notícias

- Campanha Negativa

- Tentativa de Criar Engajamento

Pessoal/Intimidade

Promessas e Propostas

nealizações Passadas

Outros

Fonte: O autor (2016) 
- Gráfico 6: Marina Silva - Análise de conteúdo - Replicações
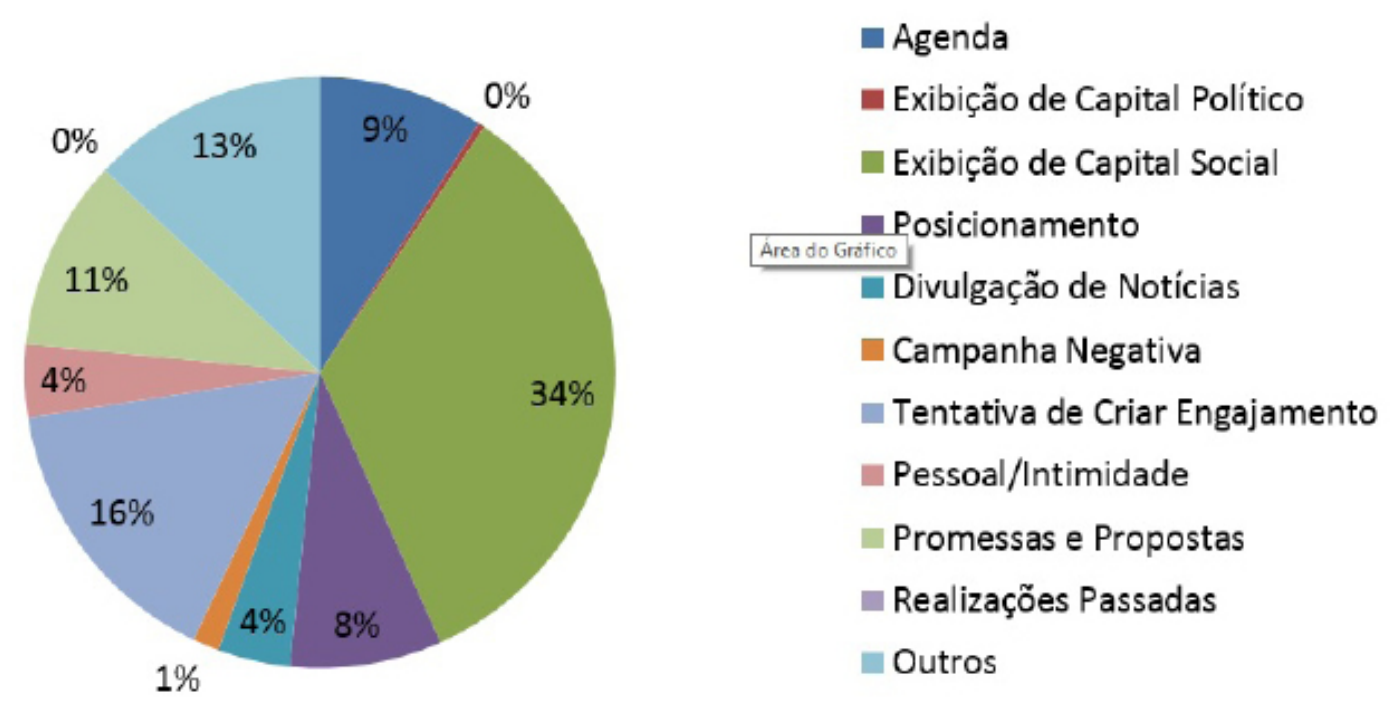

Fonte: $O$ autor (2016)

Ao menos na dimensão das interações através de menções, portanto, a campanha da então candidata do Partido Verde usou de sua comunicação direta para o esclarecimento de seus eleitores enquanto suas posições frente à questões públicas e propostas de governo. Foi também através da comunicação horizontal com terceiros que a campanha de Marina Silva imprimiu esforços na tentativa de criar engajamento, dedicando $17 \%$ do total de mensagens contendo menções.

No cenário das replicações de mensagens, a distribuição da funcionalidade dos tweets se deu de outra forma. Dos 277 retweets feitos pela campanha de Marina Silva, 94 ou 34\% do total destinaram-se à exibição de capital social. Pressupõe-se que a estratégia de reproduzir mensagens, interagindo discursivamente com o autor do tweet ou não, seja o mecanismo mais eficiente para exibir o prestígio social do candidato, uma vez que permite a exposição dos enunciados elogiosos a todos seus seguidores.

"Propostas", "outros" e estímulo ao engajamento permaneceram entre as quatro categorias com maior repetição no conjunto de mensagens compostas com retweets, assim como nas menções. Essa repetição reforça a hipótese de que ambos os recursos para a interação discursiva foram dedicados a temas de natureza política, mas que também conviveram com tópicos diversos externos à política. 


\title{
Gráfico 7: Marina Silva - Análise de conteúdo - Recursos para interação
} discursiva

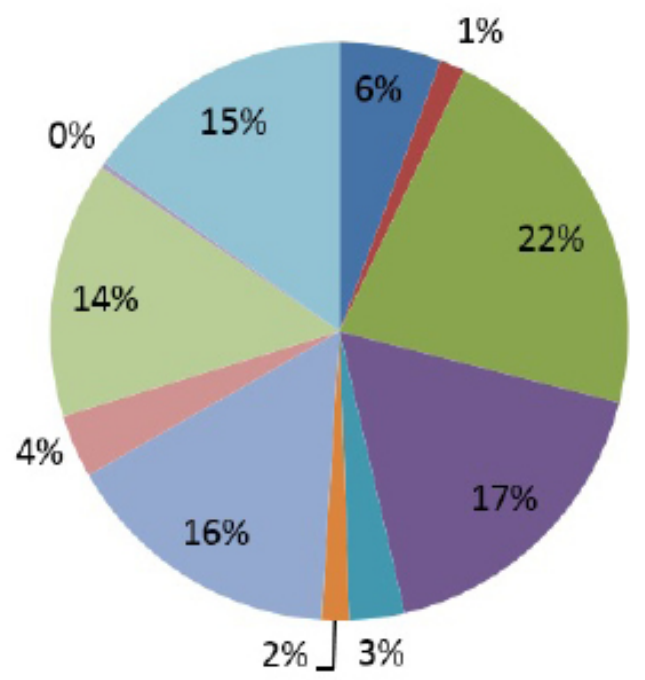

\author{
Agenda \\ - Exibição de Capital Político \\ Exibição de Capital Social \\ Posicionamento \\ - Divulgação de Notícias \\ - Campanha Negativa \\ - Tentativa de Criar Engajamento \\ - Pessoal/Intimidade \\ Promessas e Propostas \\ - Realizações Passadas
}

Outros

Fonte: O autor (2016)

É o que demonstra o gráfico acima. Na soma das mensagens com menções e replicações, destaca-se a exibição de capital social como a estratégia principal seguida de tweets com posicionamentos, tentativa de criar engajamento e "outros". É necessário salientar que, apesar da categoria "promessas e propostas" não figurar entre as quatro primeiras, sua diferença para a última melhor posicionada é de apenas cinco tweets. "Outros" representa a fatia de $15 \%$ do total enquanto as mensagens contendo propostas representam 14\%, o que reforça a importância das interações discursivas para a discussão de temas políticos na campanha de Marina Silva.

\section{José Serra}

JoséSerra optou pela estratégia de interagir informalmente. As mensagens classificadas na categoria "outros" ocuparam o primeiro lugar nas postagens do candidato do PSDB. O equivalente ao dobro da quantidade de mensagens da segunda categoria mais frequente, "agenda". $36 \%$ de todos os tweets do candidato do PSDB que fazem referência a algum perfil mediante o mecanismo de menções serviu para se aproximar de eleitores através comentários sobre questões cotidianas e temas apolíticos. 
Gráfico 8: José Serra - Análise de conteúdo - Menções

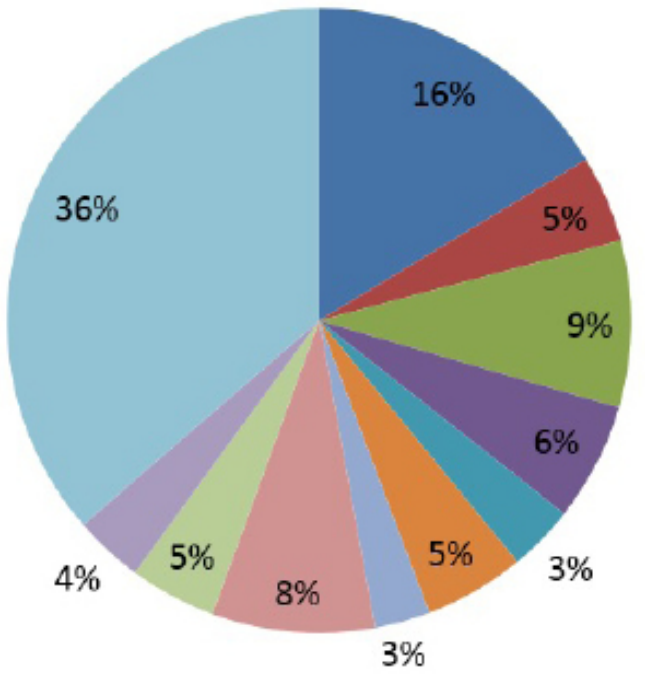

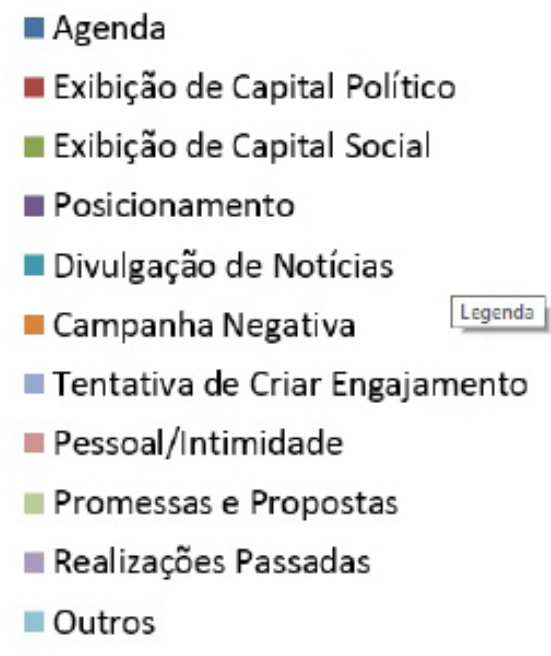

Fonte: O autor (2016)

Seguindo a tendência já constatada no caso de Marina Silva, há uma relação direta entre o uso do Twitter e a exibição de capital social no tocante às interações discursivas. Conforme exposto no Gráfico 8, as mensagens voltadas à exibição do prestígio social de José Serra ocuparam a terceira categoria mais frequente, apenas superada pelas categorias "agenda" e "outros". José Serra também buscou ou aproveitou a interação com eleitores para tratar de aspectos de sua biografia, de suas preferências pessoais e destacar fatos e situações do cotidiano de suas relações e atividades privadas. A categoria de mensagens "pessoal e intimidade" ocupou a quarta posição em termos de frequência, ou $8 \%$ do total das mensagens com menções.

No cenário de mensagens replicadas no perfil de José Serra, as três categorias mais predominantes entre as menções se mantém, embora tenha havido mudanças na ordem de frequência. A única alteração significativa foi a substituição da categoria "pessoal e intimidade" pela categoria "exibição de capital político" entre as quatro categorias mais presentes no conjunto das mensagens.

Assim como no caso de Marina Silva, o candidato do PSDB atribui a seus retweets a função de exibir e interagir com manifestações de terceiros que contribuíssem para a exibição de seu capital social. 39\% de todas as mensagens com replicações foram voltadas a essa finalidade. A categoria "outros" ficou na segunda posição e manteve-se mais frequente que a categoria "agenda", assim como nas mensagens com menções. No entanto, José Serra aproveitou 
mensagens de outros perfis mencionando apoios e divulgando alianças com o candidato para exibir seu capital político a seus seguidores.

q Gráfico 9: José Serra - Análise de conteúdo - Replicações

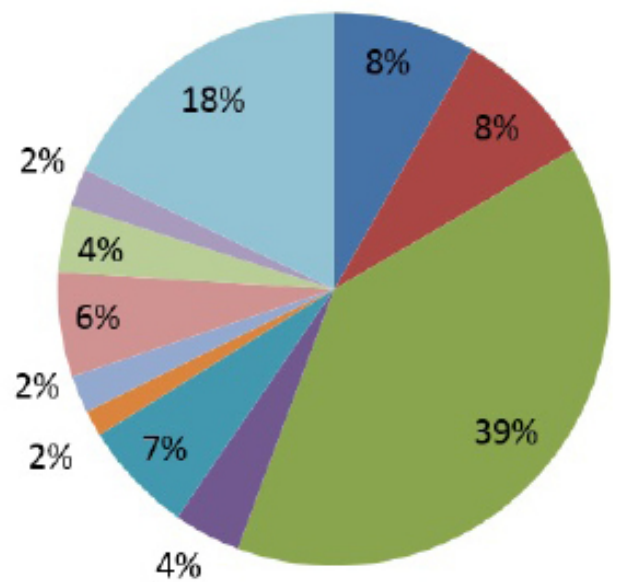

$$
\begin{aligned}
& \text { " Agenda } \\
& \text { n Exibição de Capital Político } \\
& \text { n Exibição de Capital Social } \\
& \text { n Posicionamento } \\
& \text { n Divulgação de Notícias } \\
& \text { n Campanha Negativa } \\
& \text { n Tentativa de Criar Engajamento } \\
& \text { n Pessoal/Intimidade } \\
& \text { n Promessas e Propostas } \\
& \text { n Realizações Passadas } \\
& \text { n Outros }
\end{aligned}
$$

Fonte: O autor (2016)

No conjunto das duas formas de interação discursiva, percebe-se que a ênfase dada às quatro categorias das menções se mantém como mais frequentes. A análise da soma das mensagens contendo mentions e retweets demonstra que a interação entre o perfil de José Serra e outros perfis priorizou: (a) temas triviais e apolíticos, (b) exibição de capital social, (c) agenda e (d) informações de caráter pessoal e íntimo.

Dentre os tipos de mensagens menos frequentes é possível evidenciar que o Twitter não serviu para a campanha de José Serra como instrumento para orientar simpatizantes e outros eleitores em ações de engajamento Esclarecimentos sobre o posicionamento do candidato frente a questões públicas e a divulgação de promessas e propostas também não foram razões prioritárias na comunicação direta. "Posicionamento" representou 5\% do total das mensagens com interação discursiva e "Promessas e Propostas" apenas 4\%. 
Gráfico 10: José Serra - Análise de conteúdo - Recursos para interação discursiva

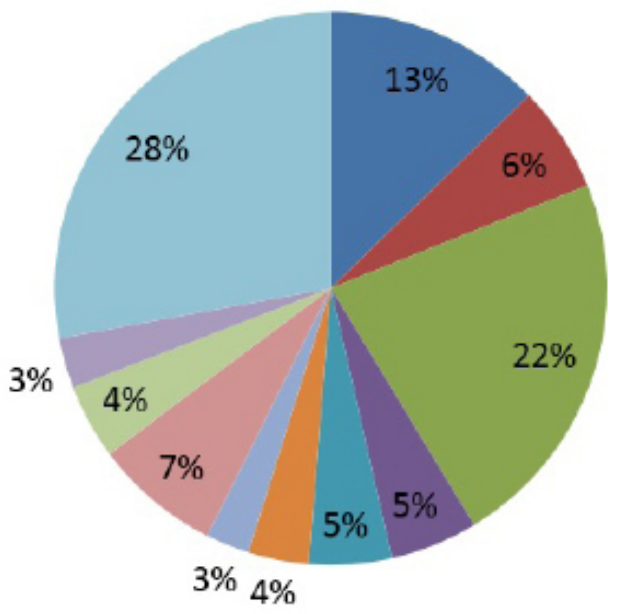

\begin{tabular}{|c|}
\hline Agenda \\
\hline Exibição de Capital Político \\
\hline Exibição de Capital Social \\
\hline Posicionamento \\
\hline Divulgação de Notícias \\
\hline Campanha Negativa \\
\hline Tentativa de Criar Engajamento \\
\hline — Pessoal/Intimidade \\
\hline Promessas e Propostas \\
\hline Realizações Passadas \\
\hline Outros \\
\hline
\end{tabular}

Fonte: O autor (2015).

\section{Dilma Rousseff}

A candidata do PT dedicou apenas 69 de todos os seus 392 tweets à inserção de recursos para a interação discursiva. Dado o baixo índice de mensagens contendo menções e replicações, algumas categorias de conteúdo não foram contempladas sequer uma vez. No conjunto de tweets com menções, "divulgação de notícias", "campanha negativa", "engajamento" e "promessas e propostas" não foram temas de nenhum tweet, conforme demonstra o gráfico abaixo.

\section{Gráfico 11: Dilma Rousseff - Análise de conteúdo - Menções}

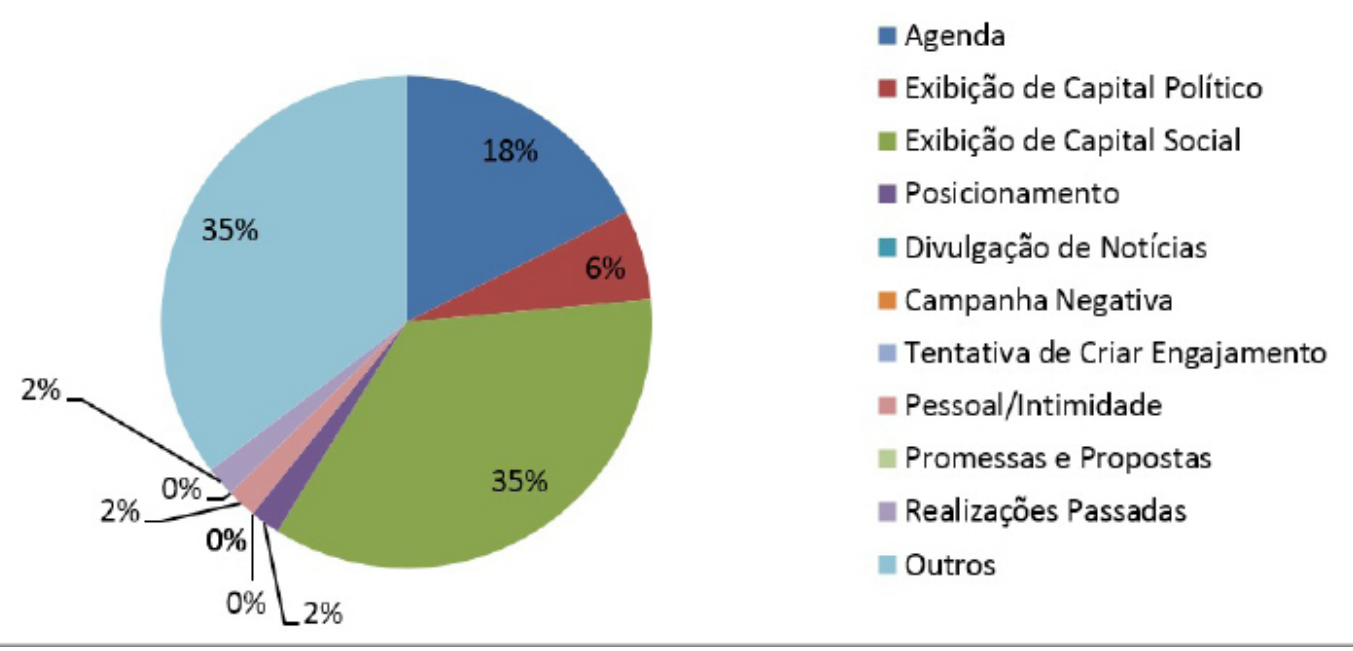

Fonte: O autor (2016). 
A candidata do PT inverte a tendência esboçada por seus dois adversários no tocante à funcionalidade das mensagens com menções. Ao contrário Marina Silva e José Serra, que prefiram usar as replicações com esse intuito, Dilma Rousseff escolheu as menções a outros perfis para exibir capital social. Esse recurso divide o primeiro lugar em número de frequência ao lado da categoria "outros". Assim como fez José Serra, houve um destaque para menções voltadas a comentários ou divulgação de eventos de campanha da candidata do PT, mas diferentemente de seu adversário, que preferiu usar retweets para exibir seu prestígio político, Dilma o fez a partir dos mentions.

A escala de prioridades estratégicas das replicações foi distinta. A campanha de Dilma manteve as conversas triviais com outros perfis, assim como a exibição de capital social e tópicos sobre agenda, mas acrescentou entre as quatro maiores prioridades a divulgação de posicionamentos, como demonstra o gráfico 12.

Nas mensagens contendo replicações da candidata Dilma Rousseff, cinco categorias de mensagens foram ignoradas: (a) divulgação de notícias, (b) tentativa de criar engajamento, (c) pessoal e intimidade, (d) promessas e propostas e (e) realizações passadas.

\title{
Gráfico 12: Dilma Rousseff - Análise de conteúdo - Replicações
}

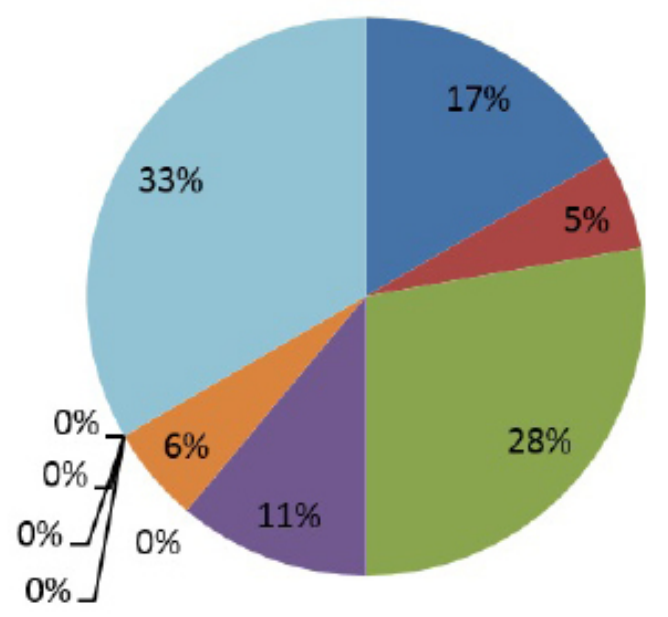

\author{
- Agenda \\ - Exibição de Capital Político \\ n Exibição de Capital Social \\ posicionamento \\ - Divulgação de Notícias \\ - Campanha Negativa \\ - Tentativa de Criar Engajamento \\ - Pessoal/Intimidade \\ - Promessas e Propostas \\ nealizações Passadas \\ nutros
}

Fonte: O Autor (2016).

Na distribuição geral dos recursos para a interação discursiva, predominou a ordem classificatória das menções, invertendo apenas a posição da exibição de capital social, que passou para segunda posição dando lugar a "outros". 
As categorias "divulgação de notícias", "tentativas de criar engajamento" e "promessas e propostas" não foram contempladas em nenhuma ocasião de publicação das mensagens com menções e com replicações.

Somando as mensagens contendo replicações e menções dos três candidatos, percebe-se que as interações discursivas serviram, majoritariamente, ao propósito de exibição de capital social (23\%) e considerações sobre temas aleatórios externos à política. Em seguida figuraram as categorias "agenda" e "posicionamento", cada uma com 10\%. "Promessas e propostas" foram responsáveis por apenas $8 \%$ das interações entre campanhas e outros usuários do Twitter.

Gráfico 13: Dilma Rousseff - Análise de conteúdo - Recursos para interação discursiva

\section{Dilma Rousseff - Análise de conteúdo dos recursos para interação discursiva}

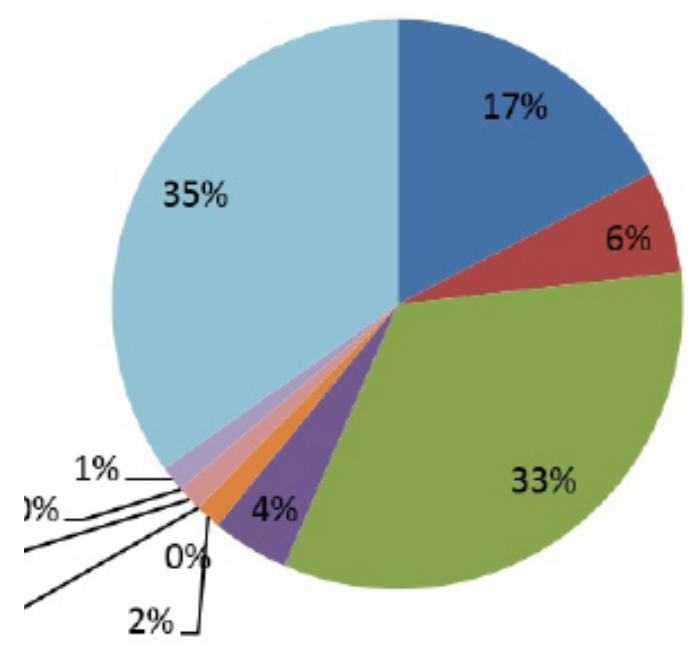

- Agenda

- Exibição de Capital Político

Exibição de Capital Social

- Posicionamento

n Divulgação de Notícias

- Campanha Negativa

- Tentativa de Criar Engajamento

nessoal/Intimidade

- Promessas e Propostas

nealizações Passadas

moutros

Fonte: O autor (2016). 


\section{Gráfico 14: Quadro Geral - Análise de conteúdo - Recursos para interação} discursiva
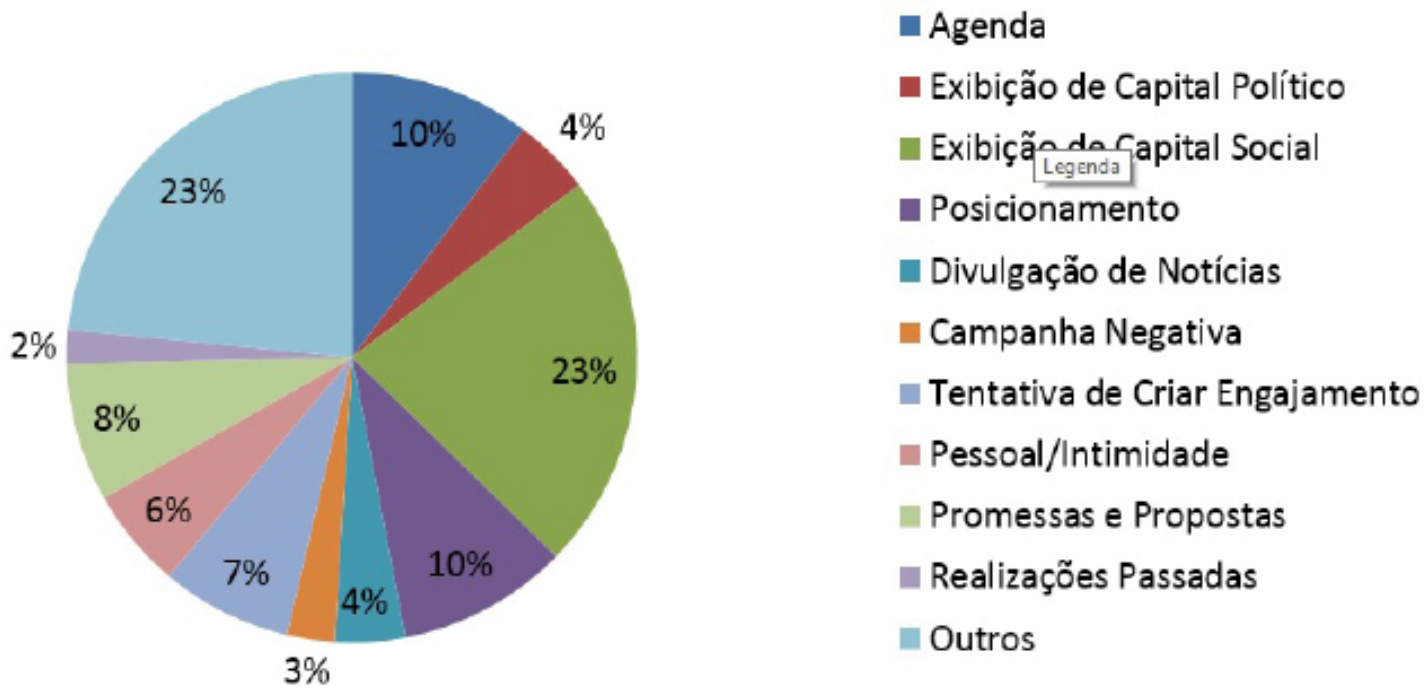

Fonte: O autor (2016).

\section{Recursos para a interação: 0 aparente e o efetivo}

Conforme exposto anteriormente, foram criados dois indicadores para as variáveis "menção" e "replicação". Julga-se neste trabalho, em chave crítica, que a simples constatação de mention e retweets não são suficientes para atestar o contato direto entre campanhas, eleitores e outros atores sociais e políticos. $\mathrm{O}$ exemplo abaixo ilustra bem os casos em que menções não configuram uma interação direta entre o autor da mensagem e os mencionados. Nem mesmo há indícios seguros de que a menção foi orientada por alguma intenção de interagir. A campanha de Marina Silva apenas trocou uma menção nominal pela menção às contas de seus dois adversários. Tal ação, por exemplo, não foi seguida da reação de nenhum dos dois mencionado, ou seja, sequer serviu como estímulo para a comunicação direta:

"Às vezes eu fico me perguntando se fazem esta pergunta também para a @dilmabr e para o @joseserra_ _http://migre.me/AOc1>" (Tweet publicado no perfil de Marina Silva em 30 de abril de 2010"

Retweets são recursos que possibilitam interações discursivas, mas também são, por excelência, o mecanismo para que usuários do Twitter compartilhem, almejando fins diversos, mensagens e informações publicadas por terceiros como forma de divulgar uma informação ou endossar uma afirmativa. Todos os 
três candidatos, em alguma medida, utilizaram tal recurso com essa finalidade, como ilustra o exemplo de José Serra abaixo:

\footnotetext{
“Rt @TukaScaletti @joseserra_Fernando Girão - Na Baixa do sapateiro - Video Clip Oficial <http://youtu.be/tcLns-PRWok>" (Tweet publicado no perfil de José Serra em 3 de agosto de 2010)
}

Não obstante as funcionalidades ilustradas acima, os dois recursos podem ser utilizados, efetivamente, para a interação direta e discursiva. Distinguir essas duas formas de utilização é tarefa crucial para determinar o nível de interatividade das campanhas online no Twitter.

Foram consideradas como interações discursivas quaisquer mensagens cujos enunciados demonstrassem haver respostas ou quaisquer reações discursivas dos candidatos ao mencionar um perfil ou reproduzir mensagens de terceiros. Marina Silva foi a candidata que mais interagiu efetivamente. $90 \%$ das menções feitas pela candidata e $70 \%$ das mensagens com replicações contiveram interações discursivas.

\section{Gráfico 15: Marina Silva - Interções Discursivas Efetivas}

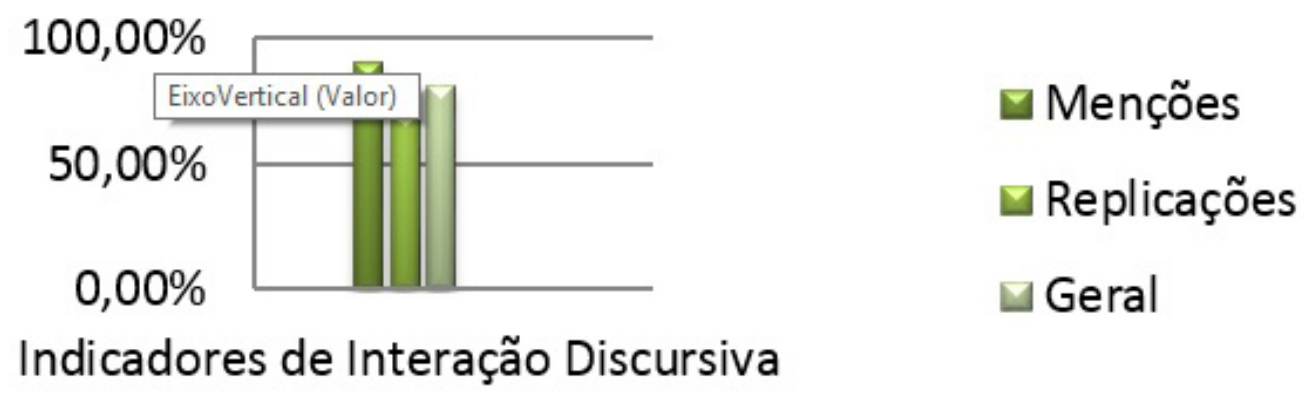

Fonte: O autor (2016).

Conforme demonstrado no gráfico $15,81 \%$ de todas as mensagens de Marina Silva contendo mentions e retweets, representam, efetivamente, registros de interações discursivas. Dilma Rousseff interagiu em 78,4\% das mensagens contendo menções e em $55,6 \%$ das publicações contendo retweets. Na soma geral das menções e replicações, a candidata do PT estabeleceu interações discursivas em $72,4 \%$ das vezes. 
Gráfico 16: Dilma Rousseff - Interações Discursivas Efetivas

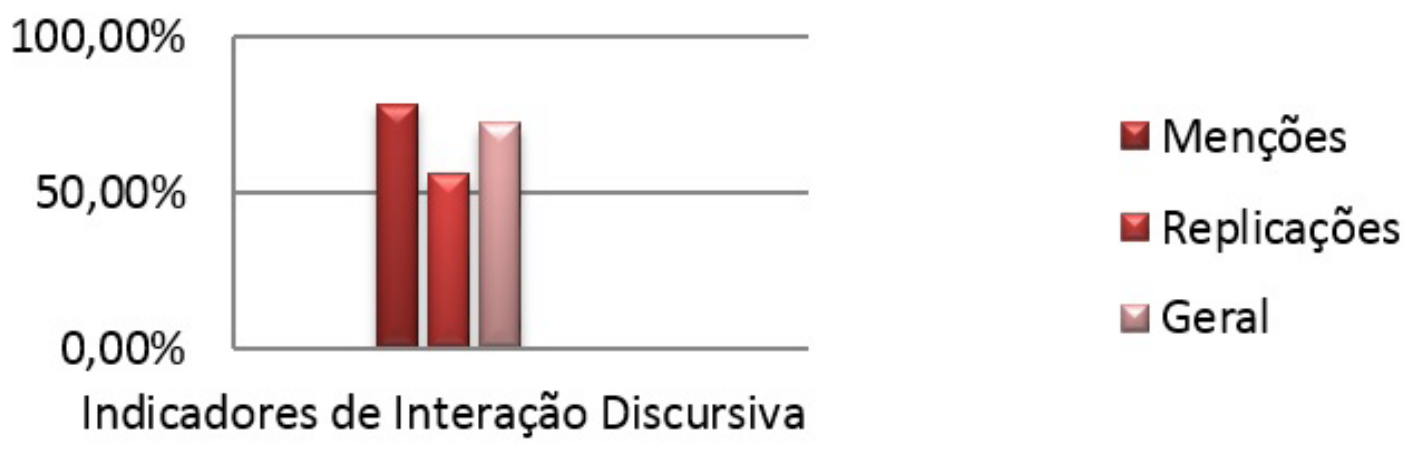

Fonte: O autor (2016).

José Serra figura como o segundo candidato que mais interagiu efetivamente com usuários do Twitter. No universo das menções, $82,2 \%$ das mensagens, de fato, contemplaram discursivamente manifestações de terceiros. No que tange aos retweets, $61,10 \%$ se constituíram como interações discursivas. No total, $72,2 \%$ de todas as mensagens contendo os recursos para a interação discursiva efetivamente serviram a esse propósito.

\section{Gráfico 17: José Serra - Interações Discursivas Efetivas}

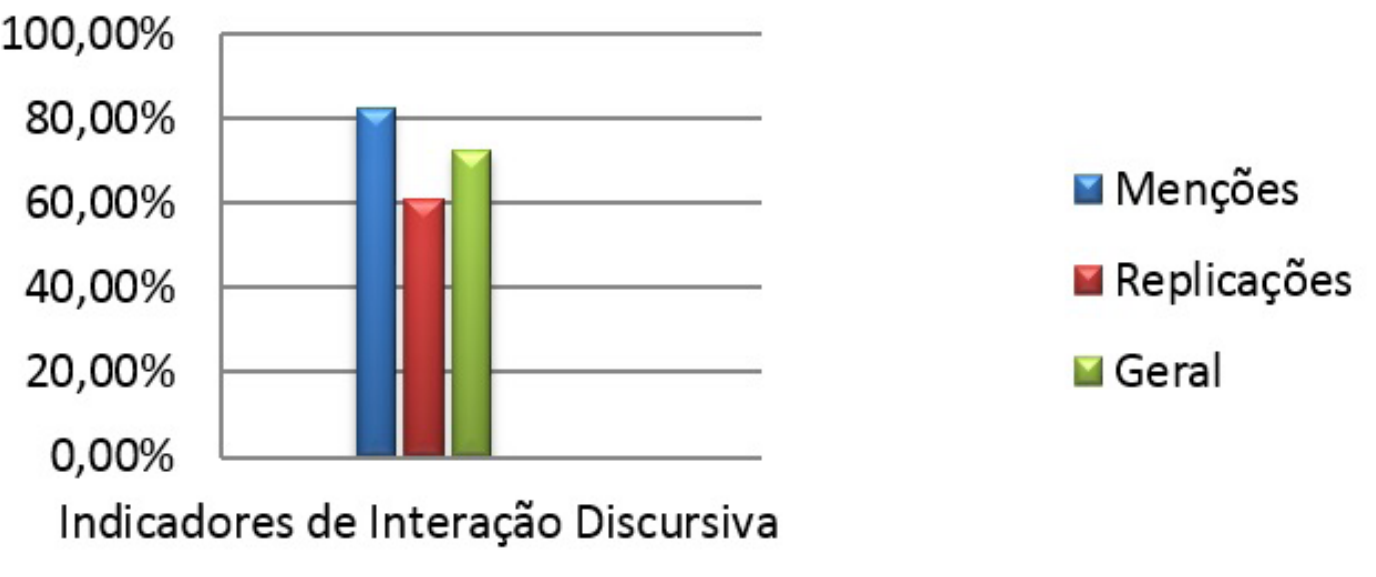

Fonte: O autor (2016).

Os dados dos três candidatos evidenciam semelhanças nas funções atribuídas aos dois recursos. Embora José Serra tenha sido o candidato que se destacou na utilização das menções e replicações para definir o estilo de sua comunicação no Twitter, quem se destacou, efetivamente, no contato direto e discursivo com eleitores e demais perfis no Twitter foi a candidata do 
Partido Verde, Marina Silva. Embora com atuação pouco expressiva em termos interativos, Dilma Rousseff interagiu genuinamente com outros usuários do Twitter na grande parte das vezes em que utilizou esses recursos: $72,4 \%$.

\section{Gráfico 18: Geral - Interações Discursivas Efetivas}

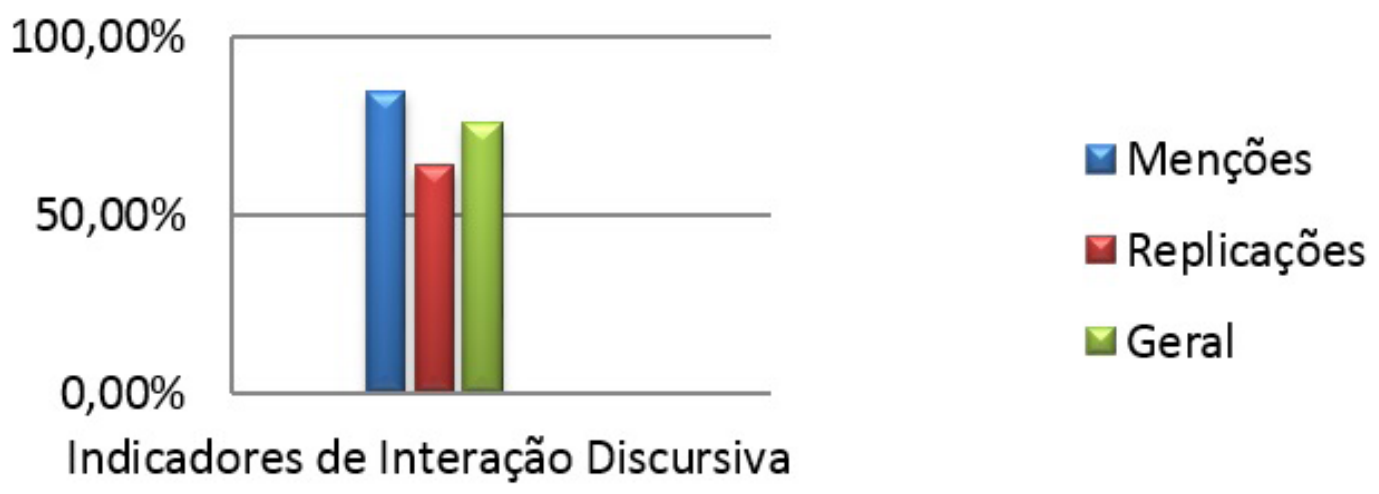

Fonte: O autor (2016).

\section{Considerações finais}

No que se refere ao volume de mensagens com menções e replicações presentes no conjunto de tweets dos três candidatos - e tomando a presença desses recursos como indícios de interação dialógica - o modelo brasileiro de campanha presidencial no Twitter de que dispomos até o momento respeita um padrão que segue os melhores números encontrados em experiências mundiais, uma vez que quase metade de todas as mensagens publicadas pelas três campanhas foi composta de mentions e retweets. Trata-se de um modelo que equivale, proporcionalmente, as estratégias de comunicação horizontal no Twitter às mensagens do tipo "broadcasting", voltadas para a divulgação de algum tipo de informação ou exibição de conteúdo sem qualquer indício e propósito de interação discursiva.

Aproximadamente $48 \%$ da soma de todas as mensagens publicadas pelos três candidatos possuíam os recursos para menção e replicação. A constatação de que quase metade de todos os tweets publicados pelos três principais candidatos à presidente em 2010 foi composta com recursos para a interação discursiva, conduz à conclusão de que o Twitter foi apropriado, conceitual e estrategicamente, como um canal de interação direta com o público na mesma medida em que serviu para a divulgação de informações.

Considerando os resultados das análises empíricas realizadas neste artigo, a eleição para presidente do Brasil de 2010 teve média superior ao registrado na 
literatura: quase $80 \%$ dos $48 \%$ de presença de mentions e retweets da soma dos três candidatos da amostra consistiram em interações discursivas efetivas entre as campanhas e outros perfis no Twitter.

Metodologicamente, pretendeu-se demonstrar a necessidade de aprofundar a análise qualitativa das interações no Twitter para evitar inconsistências analíticas e conclusões questionáveis sobre a real interatividade das campanhas online.

Se forem consideradas as insuficiências metodológicas da maioria das pesquisas empíricas dedicadas à análise de campanhas noTwitter, a discrepância entre o quantitativo de interações discursivas aferidas neste trabalho em face ao padrão internacional pode ser ainda maior. Isto porque na ausência de análises pormenorizadas dos enunciados de mensagens contendo retweets e mentions é plausível cogitar que a mera constatação da presença desses recursos camufle o real nível de interação entre campanhas e o público. Em outras palavras, aquelas campanhas consideradas interativas, graças ao alto nível de presença de replicações e menções podem se mostrar menos interativas do que se supõe.

Trata-se de uma marca significativa, mas que deve ser ponderada sobre outras premissas e questões teóricas que permeiam a pesquisa em campanhas online. Conforme foi demonstrado nas análises presentes na seção empírica, apenas a candidata Marina Silva, do PV, dedicou a maior parte da comunicação direta que estabeleceu com eleitores para esclarecer e discutir ideias. No quadro geral das interações discursivas dos três candidatos, predominou, majoritariamente, a abordagem de assuntos informais como estratégia de aproximação ao eleitor a partir de temas presentes em seus cotidianos ou de simples considerações acerca de temas transversais à política.

Esta constatação demonstra que, embora o Twitter tenha sido usado significativamente para a comunicação horizontal, os três candidatos pouco contribuíram para concretizar umas das reivindicações teóricas que se faz às campanhas políticas nos meios digitais: promover a troca argumentativa entre candidatos e cidadãos acerca de temas políticos relevantes na agenda do debate público, gerando ganhos cognitivos e, consequentemente, políticos para as partes envolvidas e para o próprio processo político-eleitoral e democrático. Trata-se, portanto, da reivindicação por maior participação cidadã no jogo político a começar pela disputa eleitoral.

Finalmente, acredita-se que este trabalho tenha contribuído metodologicamente para pesquisas futuras ao lançar luz sobre a necessidade de utilização de mais abordagens analíticas a fim de medir, realmente, o quão dialógico ou discursivo são as campanhas online geridas no Twitter. Sustento, por fim, que há uma demanda internacional de pesquisas que analisem o 
quanto efetivamente o Twitter está sendo utilizado por campanhas para que se aproximem de cidadãos e grupos sociais variados para além da mera análise quantitativa de recursos que, sozinhos, apenas sugerem a existência de interações diretas. Ademais, há que se verificar a qual ou quais funções políticas, sob o ponto de vista estratégico e da racionalidade da democracia, a interação direta entre partidos, candidatos e o público está servindo.

\section{Referências}

AGGIO, Camilo. Campanhas on-line: o percurso da formação das questões, problemas e configurações a partir da literatura produzida entre 1992 e 2009. In: MARQUES, F. P. J. A.; SAMPAIO, R. C ; AGGIO, Camilo (Org.). Do clique à urna: Internet, redes sociais e eleições no Brasil. 1. ed. Salvador: EDUFBA, v.1, p. 290-350, 2013.

ARAGÓN, Pablo; KAPPLER, Karolin Eva; KALTENBRUNNER, Andreas; LANIADO, David; VOLKOVICH, Yana. Communication Dynamics in Twitter During Political Campaigns: The Case of the 2011 Spanish National Election. Policy and Internet. v.5, n.2, p. 183-206, 2013.

BAXTER, Graeme; MARCELLA, Rita. Online Parliamentary Election Campaigns in Scotland: A decade of Research. E-Journal of eDemocracy and Open Government, v.5, n.2, p. 107-127, 2012.

BRUNS, Axel; HIGHFIELD, Tim. Political Networks on Twitter. Information, Communication \& Society, v.5, n.16, p. 667-691, 2013.

BURSON-MARSTELLER. Twiplomacy. Disponível em: <http://brasil.bm.com/releases/ twitter-e-a-rede-social-favorita-dos-lideres-do-governo/>. Acesso em: 08/10/2015.

CARLSON, Tom; GÖRAN, Djupsund. Old Wine in New Bottles? The 1999 Finnish Election Campaign on the Internet. The Harvard International Journal of Press/ Politics; v.6, n.1, p. 68-87, 2001.

CONWAY, Bethany Anne; KENSKI, Kate; WANG, Di. Twitter Use by Presidential Primary Candidates During the 2012 Campaign. American Behavioral Scientist, v.57, n.11, p. 1596-1610, 2013.

DAVIS, Richard; OWEN, Diana. New Media and American Politics. Oxford: Oxford University Press, 1998.

DRUCKMAN, James N.; KIFER, Martin J; PARKIN, Michael.The Technological Development of Congressional Candidate Websites: How and Why Candidates Use Web Innovations. Social Science Computer Review; v.25, n.4, p. 425-442, 2007.

ENLI, Gunn Sara; SKOGERBO, Eli. Personalized Campaigns in Party-Centred Politics. 
Information, Communication \& Society, v.16, p. 5, p. 1-18, 2013.

FARNSWORTH, Stephen J.; OWEN, Diana. Internet use and the 2000 presidential election. Electoral Studies, v.23, n.3, p. 415-429, 2004.

FERNANDEZ, Rogério Garcia. Campanhas Eleitorais Brasileiras na Internet.

Dissertação.2005. 145 f. (Mestrado em Ciência Política do Instituto de Filosofia da Universidade Estadual de Campinas) - Instituto de Filosofia e Ciências Humanas, UNICAMP, Campinas, 2005.

GIBSON, Rachel K.; MARGOLIS; RESNICK, Michael; WARD, Stephen J. Election campaigning on the wWw in the USA and UK: A Comparative Analysis. Party Politics, v.9, n.1, p. 47-75, 2003.

GOMES, W. S.; FERNANDES, Breno; REIS, Lucas; SILVA, Tarcizio. "Politics 2.0”: A campanha on-line de Barack Obama em 2008. In: MARQUES, F. P. J. A.; SAMPAIO, Rafael C.; AGGIO, Camilo (Org.). Do clique à urna: Internet, redes sociais e eleições no Brasil. Salvador: EDUFBA, p. 63-90, 2013.

GOMES, W.; REIS, Lucas; DUARTE, Marília; MARQUES, Maurício. O Twitter na campanha eleitoral de 2010. Anais do IV Congresso da Compolítica. Rio de Janeiro: UFRJ, 2010.

GRAHAM, Todd; BROERSMA, Marcel; HAZELHOFF, Karin; van't Haar, GUIDO. Between Broadcasting Political Message and Interacting with Voters. Information, Communication \& Society, v.16, n.5, p. 692-716, 2013.

GRUSELL, Marie; NORD, Lars. Three Attitudes to 140 Characters: The Use and Views of Twitter in Political Party Communications in Sweden. Public Communication Review. v.2, n.2, p. 48-61, 2012.

HOLOTESCU, Carmen; GROSSECK, Gabriela; BRAN, Ramona; GUTU, Dorina. The Influence of Communication in 140 Characters on Romanian Presidential Elections. Disponível em: $\leq$ http://www.ris.uvt.ro/wp-content/uploads/2010/11/ holotescuetal ris13.pdf $>$. Acesso em: 08/10/2015.

HOWARD, Philip N. Deep Democracy, Thin Citizenship: The Impact of Digital Media in Political Campaign Strategy. In: Annals of the American Academy of Political and Social Science 597, 2005.

KLINGER, Ulrike. Mastering the Art of Social Media: Swiss parties, the 2011 national election and digital challenges. Information, Communication \& Society. v.16, n.5, p. 717-736, 2013.

KLUVER, Randolph. Political Culture and Information Technology in the 2001 Singapore General Election. Political Communication, v.21, n.4, p. 435-458, 2004.

LUSOLI, Wainer; WARD, Janelle. "Politics Makes Strange Bedfellows": The Internet and the 2004 European Parliament Election in Britain. The Harvard International 
Journal of Press/Politics; v.10 n.4, p. 71-97, 2005.

MACNAMARA, Jim; KENNING, Gail. E-electioneering 2010: Trends in social media use in Australian political communication. Disponível em: $<$ https://www.academia. edu/830297/E-electioneering 2010 Trends in Social Media Use in Australian Political Communication $>$. Acesso em: 01/05/2014.

MARQUES, F. P. J. A.; AQUINO, J. A. Representação Parlamentar no Twitter: Uma abordagem quantitativa. Anais do XXII Encontro Anual da Associação Nacional dos Programas de Pós-Graduação em Comunicação (COMPÓS), Salvador: UFBA, 2013.

MARQUES, F. P. J. A. ; SILVA, F.W.O.; MATOS, N.R. . Estratégias de Comunicação Política Online: Uma Análise do Perfil de José Serra no Twitter. In: Francisco Paulo Jamil Almeida Marques, Rafael Cardoso Sampaio e Camilo Aggio. (Org.). Do clique à urna: internet, redes sociais e eleições no Brasil. 1ed.Salvador: EDUFBA, 2013, v. 1, p. 268-302.

PARK, Hun Myoung; PERRY, James L. Do Campaign Websites Really Matter in Electoral Civic Engagement? Empirical Evidence From the 2004 Post-Election Internet Tracking Survey. Social Science Computer Review, v.26, n.2, p. 190-212, 2008.

PARMELEE, John H.; BICHARD, Shannon L. Politics and the Twitter Revolution: How Tweets Influence the Relationship between Political Leaders and the Public. United Kingdom: Lexington Books, 2012.

SCHWEITZER, Eva Johanna. Election Campaigning Online: German Party Websites in the 2002 National Elections. European Journal of Communication; v.20, n.3; p. 327-351, 2005.

STROMER-GALLEY, Jennifer. Interação on-line e por que os candidatos a evitam. In: MARQUES, F., P., A.; SAMPAIO, R., C.; AGGIO, Camilo (Org.). Do Clique à Urna: Internet, redes sociais e eleições no Brasil. Salvador: EDUFBA, p. 29-62, 2013.

. Presidential Campaigning in the Internet Age. New York: Oxford University Press. 2014.

TKACH-KAWASAKI, Leslie M. Politics@Japan: Party Competition on the Internet in Japan. Party Politics, v.9, n.1, p. 105-123, 2003.

WARD, Stephen; GIBSON, Rachel. On-line and on message? Candidate websites in the 2001 General Election. British Journal of Politics and International Relations, v.5, n.2, p. 188-205, 2003. 
Recebido em: 8/10/2015

Aceito em: 14/10/2015

Endereço do autor:

Camilo de Oliveira Aggio <camiloaggio@gmail.com>

Programa de Pós-graduação em Comunicação e Cultura Contemporâneas

Faculdade de Comunicação

Universidade Federal da Bahia

Av. Barão de Geremoabo, s/no, Campus de Ondina

CEP: $40.170-115$

Salvador, BA - Brsil

Fone: (71) 3283-7072 